\title{
A novel computer-aided multivariate water quality index
}

\author{
Siong Fong Sim • Teck Yee Ling • Seng Lau • \\ Mohd Zuli Jaafar
}

Received: 6 February 2015 / Accepted: 4 March 2015 /Published online: 14 March 2015

(C) Springer International Publishing Switzerland 2015

\begin{abstract}
A computer-aided multivariate water quality index is developed based on partial least squares (PLS) regression. The index is termed as the partial least squares water quality index (PLS-WQI). Briefly, a training set was computationally generated based on the guideline of National Water Quality Standards for Malaysia (NWQS) to predict the water quality. The index is benchmarked with the wellestablished index developed by the Department of Environment, Malaysia (DOE-WQI). The PLS-WQI is a continuous variable with the value closer to $I$ indicating good water quality and closer to $V$ indicating poor water quality. Unlike other conventional indexing methods, the algorithm calculates the index in a multivariate manner. The algorithm allows rapid processing of a large dataset without tedious calculation; it can be an efficient tool for spatial and temporal routine monitoring of water quality. Although the algorithm is designed based on the guideline of NWQS, it can be easily adapted to accommodate other guidelines. The algorithm was evaluated and demonstrated on the simulated and
\end{abstract}

S. F. Sim $(\bowtie) \cdot$ T. Y. Ling $\cdot$ S. Lau

Faculty of Resource Science and Technology, Universiti

Malaysia Sarawak, 94300 Kota Samarahan, Sarawak,

Malaysia

e-mail: sfsim@frst.unimas.my

M. Z. Jaafar

Faculty of Applied Science, Universiti Teknologi MARA,

40450 Shah Alam, Selangor, Malaysia real datasets. Results indicate that the algorithm is robust and reliable. Based on six parameters, the overall ratings derived are inversely correlated to DOE-WQI. When the number of parameter is increased, the overall ratings appear to provide better insights into the water quality.

Keywords Multivariate $\cdot$ Partial least squares regression · Water quality index · National Water Quality Standards for Malaysia

\section{Introduction}

Assessment of river water quality is essentially a routine monitoring activity for many environmental protection agencies. The water quality measurements are often mathematically processed to attain a single score indicating the overall water quality status. To date, numerous water quality indices have been developed; this includes the National Sanitation Foundation Water Quality Index (NSFWQI), Bhargava method, Smith's index, British Columbia Water Quality Index (BCWQI), Overall Index of Pollution (OIP), the River Ganga Index, etc. (Poonam et al. 2013). These indexing methods primarily convert the water quality measurements according to various principles, i.e. weighted average methods, weighted geometric means, minimum operator and hybrid methods, where the transformed values are aggregated to obtain an overall rating (Brown et al. 1970; Ball et al. 1980; House and Ellis 1987; Štambuk-Giljanovi'c 1999; Pesce and Wunderlin 